Article

\title{
Evaluation of Cyclodextrins as Environmentally Friendly Wettability Modifiers for Enhanced Oil Recovery
}

\author{
Adriana Falconi Telles da Cruz ${ }^{1}$, Ramon Domingues Sanches ${ }^{1}$ (D), Caetano Rodrigues Miranda ${ }^{2}$ \\ and Sergio Brochsztain 1,* \\ 1 Centro de Engenharia, Modelagem e Ciências Sociais Aplicadas, Universidade Federal do ABC, \\ Santo André 09210-580, Brazil; adri.falconii@hotmail.com (A.F.T.d.C.); rads_rds@hotmail.com (R.D.S.) \\ 2 Instituto de Física, Universidade de São Paulo, São Paulo 05508-090, Brazil; caetano.miranda@gmail.com \\ * Correspondence: sergio.brochsztain@ufabc.edu.br; Tel.: +55-11-4996-8260
}

Received: 4 February 2018; Accepted: 1 March 2018; Published: 6 March 2018

\begin{abstract}
In the present work, the use of Cyclodextrins (CDs) as wettability modifiers for enhanced oil recovery (EOR) was evaluated. Cyclodextrins (CDs) are cyclic oligosaccharides that form inclusion complexes with various organic molecules, including $n$-alkanes. Wettability was evaluated through the contact angle $(\theta)$ of an $n$-dodecane drop in contact with a quartz surface and immersed in a $0.6 \mathrm{M} \mathrm{NaCl}$ aqueous solution containing the CDs. The quartz surface was functionalized with octadecyltrichlorosilane (OTS), rendering the surface oil-wet $\left(\mathrm{C}_{18}\right.$-quartz). Here, the $n$-dodecane, the saline solution and the $\mathrm{C}_{18}$-quartz represent the oil, the reservoir brine and an oil-wet rock surface, respectively. In the absence of $C D s$, the $n$-dodecane drops spread well over the $\mathrm{C}_{18}$-quartz, showing that the surface was oleophilic. In the presence of CDs, remarkable effects on the wettability were observed. The most dramatic effects were observed with $\alpha$-cyclodextrin $(\alpha-C D)$, in which case the $C_{18}$-quartz surface changed from oil-wet $\left(\theta=162^{\circ}\right)$ in the absence of $C D$ to water-wet $\left(\theta=33^{\circ}\right)$ in the presence of $1.5 \%(w / v) \alpha-\mathrm{CD}$. The effects of the CDs can be explained by the formation of surface-active inclusion complexes between the CDs and $n$-dodecane molecules. The CD inclusion complexes can be regarded as pseudo-surfactants, which are less harmful to the environment than the traditional surfactants employed by the petroleum industry.
\end{abstract}

Keywords: cyclodextrins; inclusion complexes; enhanced oil recovery; contact angles; wettability; Pickering emulsions

\section{Introduction}

Only about one third of the original oil in place can be recovered using conventional (primary and secondary) recovery methods, such as water-flooding. An incremental amount can be recovered from reservoirs using enhanced oil recovery (EOR) methods [1-3], also known as tertiary recovery methods. According to Lake et al. [1], EOR can be defined as additional oil recovery by the injection of materials not normally present in petroleum reservoirs. The additives used in EOR are usually added to the aqueous phase during water-flooding. An important class of additives for EOR is constituted by compounds that change the wettability of rock surfaces [4-6]. These compounds render the rock surfaces more water-wet and decrease the oil/water interfacial tension, facilitating the displacement of oil by water-flooding processes.

In the present work, we evaluate the use of Cyclodextrins (CDs) as wettability modifiers for EOR. CDs are thoroid-shaped cyclic oligosaccharides constituted by glucose units linked to each other by $\alpha-1 \rightarrow 4$ bonds $[7,8]$. The most well-known CDs are $\alpha-C D, \beta-C D$ and $\gamma-C D$, with 6,7 and 8 glucose units, respectively (Figure 1). The macrocyclic $C D$ ring displays a central cavity where various guest 
molecules can be accommodated, resulting in the formation of inclusion complexes (also known as host-guest complexes) [8]. CDs are environmentally friendly substances, in contrast to many additives employed for EOR. They are prepared from renewable raw materials, and are readily biodegradable and biocompatible $[7,8]$. In addition to EOR applications, the wettability effects of the CDs could also be exploited for the remediation of oil spills.
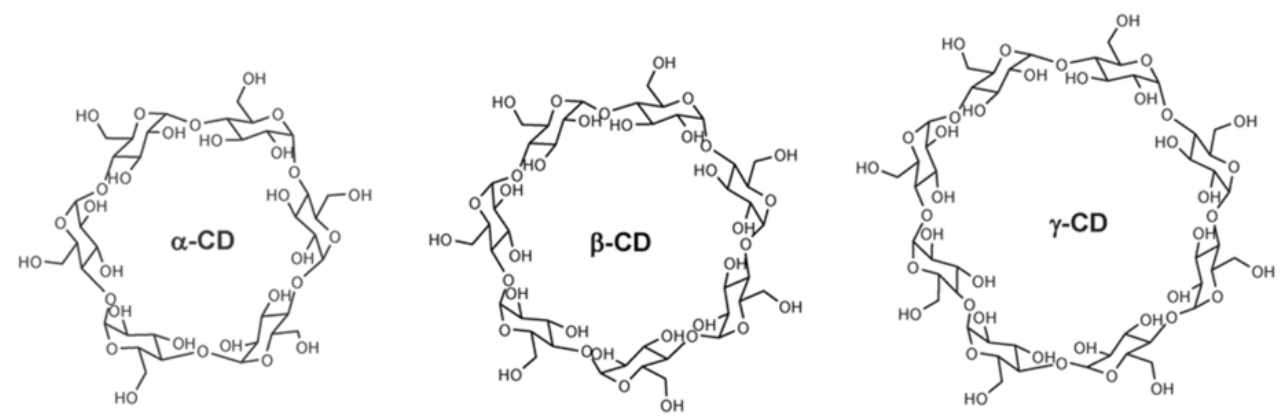

Figure 1. Structure of the most common types of cyclodextrins.

The CDs have been extensively used in the pharmaceutical industry, as well as food and cosmetic additives [7,8]. Nevertheless, there are very few reports on the use of CDs for the petroleum industry [9-13]. Some early patents described processes to extract oil from oil sands using Cyclodextrins $[9,10]$, but no further studies were found in the literature. Leslie et al. [11] used a CD-based polymer as a thickening agent for water permeability reduction in EOR. Similarly, Kjøniksen et al. [12] studied the effect of adding CDs to other polysaccharides for water permeability reduction. In those cases, however, the CD-based additives for EOR were aimed at enhancing the viscosity of the water phase [13], rather than altering the wettability.

The wettability of a triphasic oil/rock/brine system has been mainly evaluated by contact angle measurements [14-22]. In the present work, we used the arrangement shown in Figure 2 for contact angle measurements. A drop of $n$-dodecane was placed under a quartz surface, with the whole system immersed in a saline solution $(0.6 \mathrm{M} \mathrm{NaCl})$, where the $\mathrm{CDs}$ to be tested were dissolved. In this system, the quartz substrate represents the surface of sandstone rocks, the $n$-dodecane is a model for the oil phase and the saline solution simulates the reservoir brine. The contact angle $\theta$ (measured through the water phase) is then related to the interfacial tensions by the Young equation (Equation (1)), where $\gamma_{\mathrm{os}}$, $\gamma_{\mathrm{ws}}$ and $\gamma_{\mathrm{ow}}$ are the interfacial tensions between the solid (s), oil (o) and water (w) phases, as indicated in Figure 2B. If the oil drop spreads on the substrate $\left(\theta>90^{\circ}\right)$, the surface is considered oil-wet. On the other hand, if the oil has no trend to spread $\left(\theta<90^{\circ}\right)$ the surface is considered water-wet. A contact angle close to $90^{\circ}$ means an intermediate-wet surface [14-22].

$$
\gamma_{\mathrm{os}}-\gamma_{\mathrm{ws}}=\gamma_{\mathrm{ow}} \cos \theta
$$

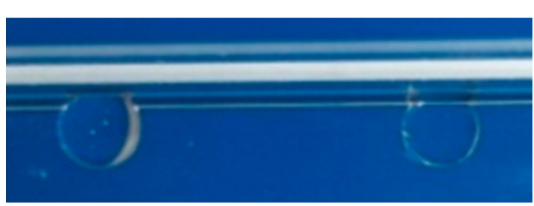

A

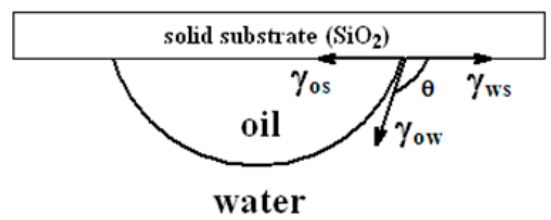

B

Figure 2. Experimental arrangement employed to measure the effect of cyclodextrins (CDs) on the contact angles. (A) Photograph showing $n$-dodecane drops in contact with the quartz surface in a cuvette filled with the aqueous phase; (B) Analysis of the drop shape according to the Young equation (Equation (1)), showing the contact-angle (through the water phase) and the interfacial tensions. The solid substrate was a modified quartz surface, the oil drop was $n$-dodecane and the aqueous phase was a brine solution $(0.6 \mathrm{M} \mathrm{NaCl})$ containing dissolved CDs. 
In a previous report [23], we showed that the CDs can increase the water wettability of quartz surfaces in a three-phase system like that of Figure 2. The observed effects of the CDs, however, were small, because the study started from pristine quartz surfaces, which were already water-wet. Pristine quartz surfaces do not reflect the actual situation found in oil reservoirs, where wettability inversion due to asphaltene deposition renders the rock surfaces oil-wet.

In the present study, we evaluate the potential of CDs for EOR employing quartz surfaces functionalized with octadecyl groups ( $C_{18}$-quartz, Scheme 1$)$. The oleophilic $C_{18}$-quartz surface is employed as a mimetic system for oil-wet rock surfaces. Remarkable wettability alterations were observed in the presence of the different $C D$ s tested. The most striking effects were observed with $\alpha-C D$, in which case the $C_{18}$-quartz changed from oil-wet in the absence of CDs to water-wet in their presence. The effects of CDs on the wettability of quartz surfaces can be attributed to the formation of inclusion complexes between the CDs and $n$-dodecane at the oil/water interface, with the hydrocarbon included in the CD cavity (Scheme 2). Recent studies have shown that the CDs are not surface-active on their own [24,25], but inclusion complexes of the CDs with linear alkanes behave as pseudo-surfactants, decreasing the oil/water interfacial tension $[25,26]$. Those studies were aiming at applications of the pseudo-surfactants in pharmaceutical and cosmetic products, which means that the present results could also be of interest of researchers in those fields.

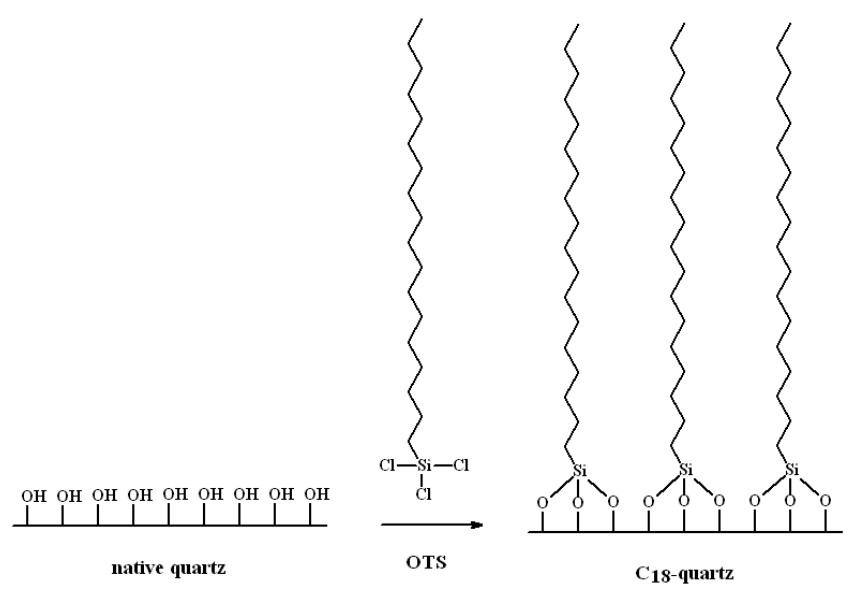

Scheme 1. Functionalization of a quartz surface with octadecyltrichlorosilane (OTS) to give oleophilic $\mathrm{C}_{18}$-quartz.
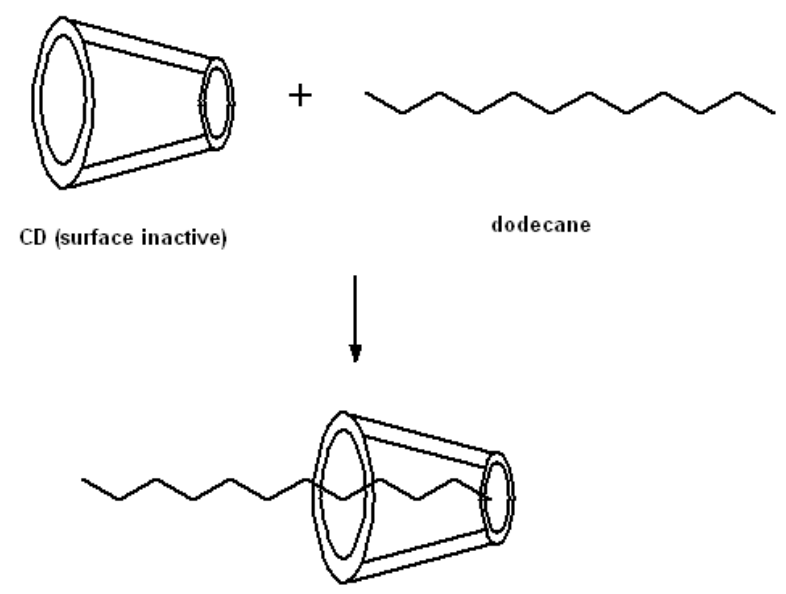

inclusion complex (surface active)

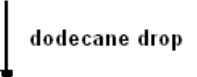

Scheme 2. Cont. 


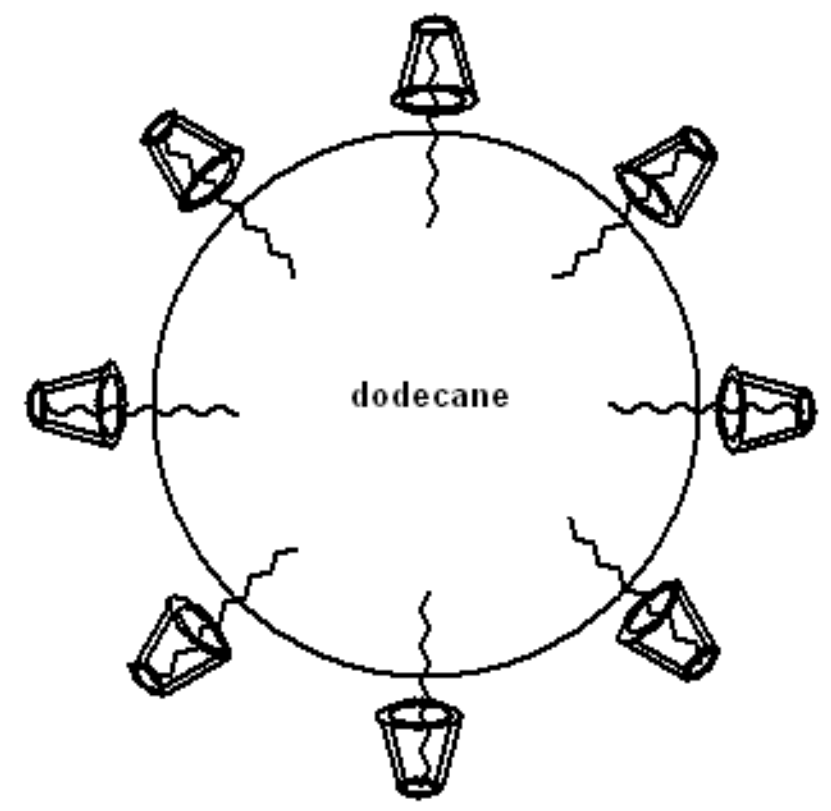

Scheme 2. Formation of inclusion complexes between CDs and $n$-dodecane, and their assembly on the oil drop surface.

\section{Materials and Methods}

\subsection{Materials}

Octadecyl trichlorosilane (OTS) was purchased from Sigma-Aldrich (St. Louis, MO, USA). Chloroform, toluene and acetonitrile were HPLC grade from J.T. Baker (Phillipsburg, NJ, USA). $\alpha$-Cyclodextrin $(\alpha-C D), \beta$-cyclodextrin $(\beta-C D)$ and $\gamma$-cyclodextrin $(\gamma-C D)$ were obtained from Fluka (Buchs, Switzerland). 2-Hydroxypropyl- $\alpha$-cyclodextrin (HP- $\alpha$-CD) (average MW 1180; 0.6 mol substitution), 2-hydroxypropyl- $\beta$-cyclodextrin (HP- $\beta$-CD) (average MW 1380; 0.6 mol substitution) and $n$-dodecane (>99\% purity) were purchased from Sigma-Aldrich. $\mathrm{NaCl}$ was supplied by Sigma-Aldrich. Aqueous solutions were prepared with deionized water (Barnstead Milli-Q system, Thermo Fisher Scientific, Waltham, MA, USA). A fluorescence cuvette (111-QS, $3600 \mu \mathrm{L}$ capacity, 10 mm path length) (Hellma Analytics, Müllheim, Germany) was used as the quartz substrate (Figure 2A). According to the supplier, the cuvette windows are made from quartz Suprasil (Heraeus Quarzglas $\mathrm{GmbH}$, Kleinostheim, Germany), which is a synthetic quartz of high purity and homogeneity.

\subsection{Instruments}

Contact angle measurements were performed with a Theta Optical Tensiometer (Biolin Scientific, Gothenburg, Sweden). The tensiometer records drop images as a function of time and analyses the drop shapes using the included software (OneAttension v2.2, Biolin Scientific). The contact angles are then calculated for individual images using the Young equation (Equation (1), Figure 2B) to fit the entire drop profile. The equipment measures the angles through the $n$-dodecane drop. In order to follow the convention, the values reported in this work are the angles through the aqueous phase (Figure 2B), which are the complementary of the measured angles $\left(\theta=180^{\circ}\right.$-measured angle). The given values are the mean between right and left contact angles for each drop. Advancing and receding contact angles were measured with the tilting cradle accessory of the tensiometer, which allows tilting of the sample stage up to $90^{\circ}$. Interfacial tension measurements were also carried out with the Theta tensiometer, using the pendant drop method, with a dodecane drop hanging from a J-shaped syringe needle inside the brine-containing aqueous CD solutions. 


\subsection{Methods}

\subsubsection{Functionalization of the Quartz Surfaces}

A solution was prepared with $40 \mu \mathrm{L}$ OTS in $10 \mathrm{~mL} n$-dodecane ([OTS] $\approx 0.01 \mathrm{M}$ ). The quartz cuvette was filled with $3 \mathrm{~mL}$ of the OTS solution and left standing for $15 \mathrm{~min}$. After that time, the solution was removed and the cuvette was thoroughly rinsed first with $n$-dodecane (8 times), than with toluene ( 6 times) and finally with chloroform (6 times). After the washing procedure the cuvette was dried with a flow of argon gas. As shown in Figure 3, the quartz surface changed from water-wet to oil-wet after the treatment.

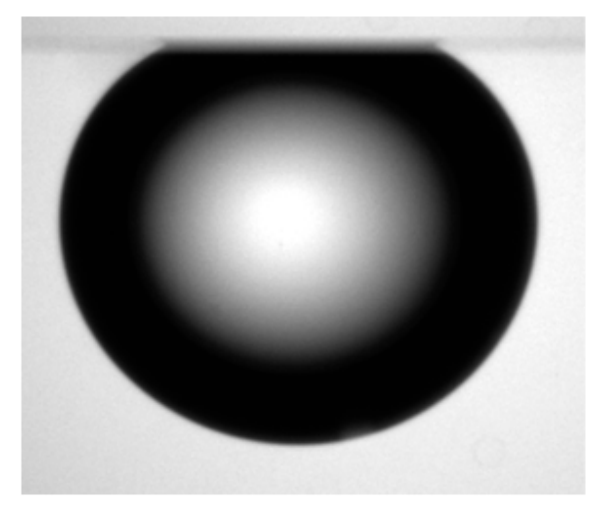

native quartz $\left(\theta=25^{\circ}\right)$

$\mathbf{A}$

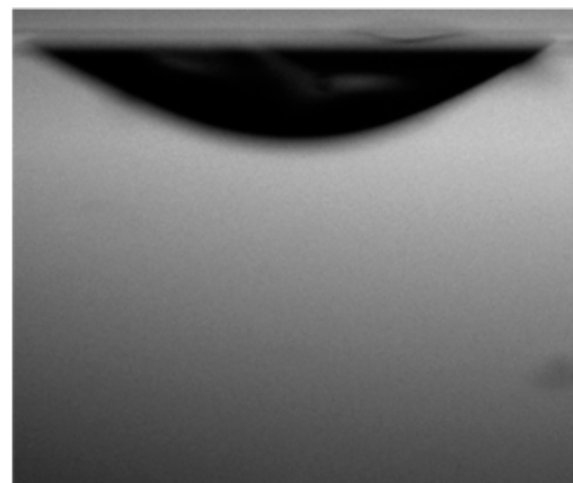

$C_{18}$-quartz $\left(\theta=162^{\circ}\right)$

B

Figure 3. Drops of $n$-dodecane immersed in the aqueous phase $(0.6 \mathrm{M} \mathrm{NaCl})$ and in contact with quartz surfaces. (A) Native quartz (before OTS treatment); (B) $\mathrm{C}_{18}$-quartz (after OTS treatment).

\subsubsection{Contact Angle Measurements}

For the measurements, the $\mathrm{C}_{18}$-quartz cuvette was filled up with the aqueous phase and then placed lying down on the sample stage of the equipment. Drops of $n$-dodecane (with ca. $6 \mu \mathrm{L}$ ) were introduced with the help of a microsyringe. Because $n$-dodecane is less dense then water, the drops detached from the needle tip and got attached to the upper cuvette wall (Figure 2A). Typically, at least three drops were deposited and analyzed in each experiment, and the average contact angle (through the aqueous phase) was reported. The experiments were performed with the cuvette open (without the PTFE stoppers), making it easy to inject the drops. Because of the surface tension of the water, the solutions did not leak out of the cuvette. Since the camera was triggered manually, it takes ca. $30 \mathrm{~s}$ between injecting the drop, positioning the cuvette and start recording the images. All measurements were performed at $25^{\circ} \mathrm{C}$, with air-equilibrated solutions $(\mathrm{pH} \approx 6$, not altered by the presence of the CDs). All CD concentrations were expressed as grams of CD per $100 \mathrm{~mL}(w / v \%)$ (a $1 \%$ solution of $\alpha-\mathrm{CD}$ or $\beta$-CD corresponds to ca. $0.01 \mathrm{~mol} / \mathrm{L}$ ).

The use of fluorescence quartz cuvettes for contact angle measurements was first proposed by Askvik et al. [27], and is a very convenient method, thanks to the optical transparency of the cuvette walls. The cuvette was washed thoroughly between experiments, first with water, then acetonitrile and finally with chloroform, and dried with a flow of argon gas. This cleaning protocol has been repeated several times and the experiments are reproducible after the treatment, indicating that the cuvette remains in its initial oil-wet condition, without OTS desorption. 


\section{Results and Discussion}

\subsection{Functionalization of the Quartz Surface}

Contact angle measurements confirmed the success of the OTS treatment. When an $n$-dodecane drop was put in contact with a native (water-wet) quartz surface in the presence of saline solution, it was observed a low tendency to spread (Figure 3A), as expected. When the same experiment was performed with $\mathrm{C}_{18}$-quartz, however, the $n$-dodecane drop showed a great affinity to the surface and tended to spread (Figure 3B). Accordingly, the contact angle changed drastically from $25^{\circ}$ in native quartz to $162^{\circ}$ in $\mathrm{C}_{18}$-quartz, confirming that a layer of OTS was chemisorbed on quartz (Scheme 1), leading to the expected wettability inversion. Grate et al. [28] reported a contact angle of $148^{\circ}$ for a similar system, composed of hexadecane drops in contact with silicon wafers modified with dodecyltriethoxysilane, which is consistent with our data, considering the different alkyl chains involved (they modified the surface with dodecyl chains).

Furthermore, $n$-dodecane drops deposited on $\mathrm{C}_{18}$-quartz were not stable. Initially, drops with high contact angle were formed, such as the one in Figure 3B. Such drops remained stable for 1 to $2 \mathrm{~min}$, and then started to collapse, spreading even more on the surface. After about $20 \mathrm{~min}$, the drops reached a final state, forming either very well spread drops with $\theta>170^{\circ}$ (Figure S2) or even films on the surface, in which case $\theta=180^{\circ}$ (there was some drop-to-drop variation). These results confirmed that the oleophilic $\mathrm{C}_{18}$-quartz surface had a great affinity for apolar hydrocarbons and therefore can be studied as an analog for reservoir rocks that underwent wettability inversion. Although structural differences exist between octadecyl-covered and asphaltene-covered surfaces, it is important to initiate the studies with a simple mimetic system composed of a pure compound, since asphaltenes isolated from petroleum are complex mixtures containing hundreds of different substances. The next step will be to test the CDs in thin films of deposited asphaltenes.

\subsection{Effect of Cyclodextrins on the Wettability of $\mathrm{C}_{18}$-Quartz}

The following results were obtained with freshly deposited drops (within $30 \mathrm{~s}$ from drop injection) and [CD] fixed at $1.5 \mathrm{~g} / 100 \mathrm{~mL}(1.5 \% w / v)$, in order to compare the effects of the different CDs in equal concentration. In a further section the effect of drop aging and varying the [CD] will be studied. As seen in Figure 4, the presence of the CDs in the aqueous phase increased the wettability of $\mathrm{C}_{18}$-quartz by water, decreasing the contact angles (Table 1). The most pronounced effect was found for $\alpha-C D$, with $\theta$ changing from $162^{\circ}$ (oil-wet) in the absence of CDs to $33^{\circ}$ (water-wet) in the presence of $\alpha$-CD (Figure 4D). Thus, $\alpha$-CD completely reversed the wettability inversion effect of the oleophilic OTS layer, resulting in drops with shape and contact angles similar to those observed with the original, unmodified native quartz (compare with Figure 3A). The other CDs tested also showed significant effects (Figure 4, Table 1), although less than in the case of $\alpha$-CD. In the presence of $\beta-C D$, intermediate wettability was observed $\left(\theta=94^{\circ}\right)$, whereas with $\gamma-C D, H P-\alpha-C D$ and HP- $\beta-C D$ the surface was slightly oil-wet $\left(\theta=110-111^{\circ}\right)$.

Table 1. Effect of different CDs on the contact angle of $n$-dodecane drops immersed in the aqueous phase and in contact with $\mathrm{C}_{18}$-quartz ${ }^{1}$.

\begin{tabular}{cc}
\hline CD & $\theta$ (Degrees) $^{2}$ \\
\hline none & 162 \\
$\alpha-C D$ & 33 \\
$\beta-C D$ & 94 \\
$\gamma-C D$ & 111 \\
HP- $\beta-C D$ & 110 \\
HP- $\alpha-C D$ & 111 \\
\hline
\end{tabular}

${ }^{1}[\mathrm{CD}]=1.5 \%(w / v)$ in all cases. Aqueous solutions contained $0.6 \mathrm{M} \mathrm{NaCl} ;{ }^{2}$ Measured through the aqueous phase. 


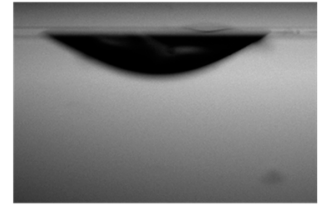

brine $\left(\theta=162^{\circ}\right)$

A

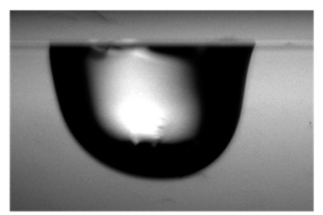

brine $+1.5 \% \beta-C D\left(\theta=94^{\circ}\right)$

C

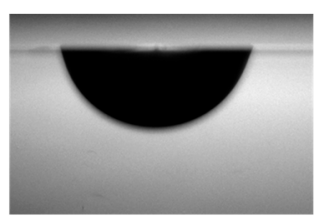

brine $+1.5 \% \gamma-\operatorname{CD}\left(\theta=111^{\circ}\right)$

B

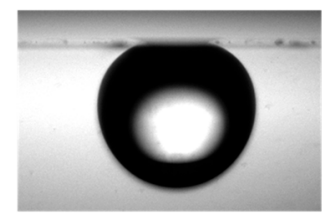

brine $+1.5 \% \alpha-\operatorname{CD}\left(\theta=33^{\circ}\right)$

D

Figure 4. Effects of the different $C D$ s on the shape of $n$-dodecane drops in contact with the $\mathrm{C}_{18}$-quartz surface and immersed in the aqueous phase containing brine $(0.6 \mathrm{M} \mathrm{NaCl})$ and the $\mathrm{CDs}$. (A) Brine only; (B) Brine $+\gamma$-CD. (C) Brine $+\beta$-CD. (D) Brine $+\alpha$-CD.

The effects of CDs can be explained by the formation of inclusion complexes at the water/n-dodecane interface (Scheme 2). It is well known that the stability of CD complexes is determined mainly by geometric factors [7,8]. Molecules having a size compatible with the dimensions of the CD cavity are likely to form stable complexes. Linear alkyl chains fit well in the small $\alpha-C D$ cavity (diameter $=5.7 \AA$ ), forming more stable complexes than the other $C D s[7,8]$, which explains why $\alpha$-CD showed the most pronounced effects in Figure 4 . $\beta$-CD (cavity diameter $=7.8 \AA$ ), on the other hand, is known to form stable complexes with simple aromatic molecules such as naphthalene, and $\gamma-\mathrm{CD}$ (cavity diameter $=9.5 \AA$ ) can form inclusion complexes with even bulkier aromatic systems $[7,8]$. Therefore, the larger CDs could in principle perform better with real asphaltenes.

According to the literature [24,25,29-31], the CDs alone are not surface active at air/water interfaces, but inclusion complexes between CDs and linear apolar molecules did present surface-activity, decreasing the air/water surface tension. Bojinova et al. [30] and Machut et al. [31] observed decreases in surface tension from $72 \mathrm{mN} / \mathrm{m}$ in pure water to values between 20 and $40 \mathrm{mN} / \mathrm{m}$ in the presence of CD complexes with 1-dodecanol and long chain esters (isosorbide dioleate and sorbitan trioleate), respectively. Similar phenomenon has been observed in oil/water interfaces $[25,26]$. Mathapa and Paunov [25] studied drops of $n$-tetradecane immersed in aqueous Cyclodextrins and reported a decrease of the water $/ n$-tetradecane interfacial tension from $44 \mathrm{mN} / \mathrm{m}$ in pure water to $37 \mathrm{mN} / \mathrm{m}$ in the presence of $1 \mathrm{mM} \alpha-\mathrm{CD}$ (ca. $0.1 \% w / v)$. Inoue et al. [26] observed a decrease in the water $/ n$-dodecane interfacial tension from $52 \mathrm{mN} / \mathrm{m}$ in pure water to $30 \mathrm{mN} / \mathrm{m}$ in the presence of $\beta-\mathrm{CD}(0.5 \% w / v)$. We realized our own measurements (Table 2, Figure S1) and found out that the brine $/ n$-dodecane interfacial tension decreased in a nearly linear fashion with $[\alpha-C D]$, from $39 \mathrm{mN} / \mathrm{m}$ in the absence of $\alpha-\mathrm{CD}$ to $32 \mathrm{mN} / \mathrm{m}$ in the presence of $0.75 \%(w / v) \alpha-C D$.

Table 2. Interfacial tension (IFT) between dodecane and $\alpha$-CD solutions of increasing concentrations ${ }^{1}$.

\begin{tabular}{|c|c|}
\hline$[\alpha-\mathrm{CD}](\% w / v)$ & IFT $(\mathrm{mN} / \mathrm{m})^{2}$ \\
\hline 0 & 39.2 \\
\hline 0.125 & 38.0 \\
\hline 0.50 & 33.4 \\
\hline 0.75 & 32.2 \\
\hline
\end{tabular}

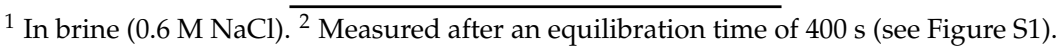


According to the Young equation (Equation (1)), a decrease in the oil/water interfacial tension $\left(\gamma_{\mathrm{ow}}\right)$ will lead to a decrease in the contact angle, rendering the surface more water-wet, as observed here. The inclusion complexes between the CDs and linear alkanes display amphiphilic character, with the $\mathrm{CD}$ as the polar head and a portion of the linear chain protruding out from the cavity as the apolar tail (Scheme 2), and can therefore be regarded as pseudo-surfactants [25,30-32], being an environmentally friendly alternative to the surfactants generally used in EOR. Another possible effect of the CDs is the formation of inclusion complexes with the octadecyl groups anchored at the $\mathrm{C}_{18}$-quartz surface, since in our experimental arrangement the $\mathrm{CD}$ was already present prior to the deposition of the hydrocarbon drop.

\subsection{Effect of $C D$ Concentration}

For EOR purposes, the additive must be active at relatively low concentrations, in order to reduce operation costs. Hence, we investigated here the effect of the $\mathrm{CD}$ concentration on the wettability of $\mathrm{C}_{18}$-quartz (Figures 5-7). At low CD concentrations, the initial contact angles (a few seconds after deposition) decreased slightly and in a linear way with CD concentration, up to a critical concentration, above which the contact angles decreased drastically from an oil-wet to a water-wet state. For $\beta-C D$, this critical concentration occurred about $1.5 \%(w / v)$ (Figures 5 and 7$)$, whereas for $\alpha$-CD it happened between $0.5 \%$ and $1.0 \%(w / v)$ (Figures 6 and 7 ), confirming that $\alpha$-CD has a more pronounced effect on wettability than $\beta-C D$. The higher efficiency of $\alpha-C D$ at lower concentrations as compared to $\beta-C D$ can be explained by the formation of stable complexes with the dodecyl chains, due to the tight fit of linear alkyl chains within the $\alpha$-CD cavity, as discussed above.

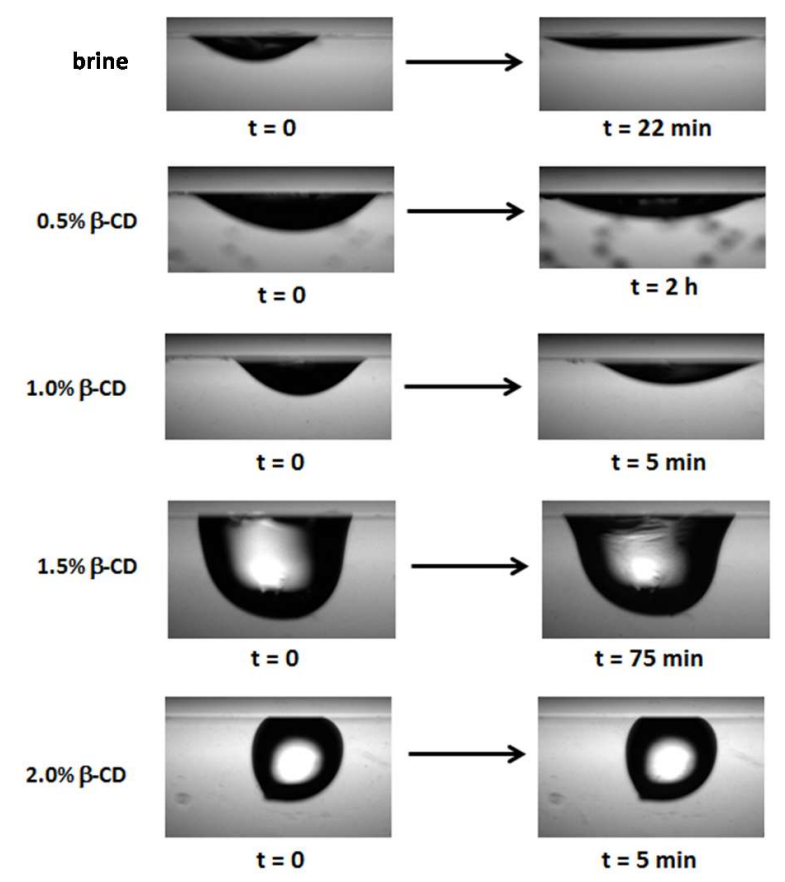

Figure 5. Drops of $n$-dodecane immersed in aqueous saline solutions $(0.6 \mathrm{M} \mathrm{NaCl})$ containing $\beta$-CD and in contact with $\mathrm{C}_{18}$-quartz. Left column: within $30 \mathrm{~s}$ after drop deposition. Right column: the same drop after the time indicated. 


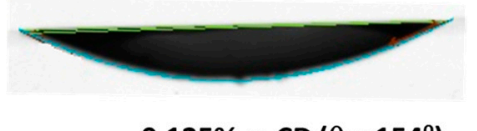

$0.125 \% \alpha-C D\left(\theta=154^{\circ}\right)$

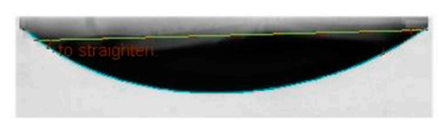

$0.5 \% \alpha-\operatorname{CD}\left(\theta=143^{\circ}\right)$

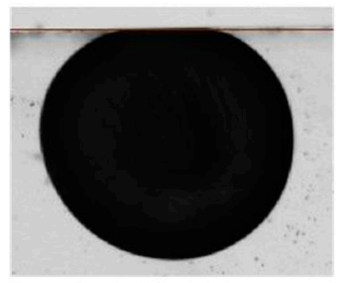

$1 \% \alpha-C D\left(\theta=23^{\circ}\right)$

Figure 6. Drops of $n$-dodecane immersed in aqueous saline solutions $(0.6 \mathrm{M} \mathrm{NaCl})$ containing $\alpha$-CD and in contact with $\mathrm{C}_{18}$-quartz.

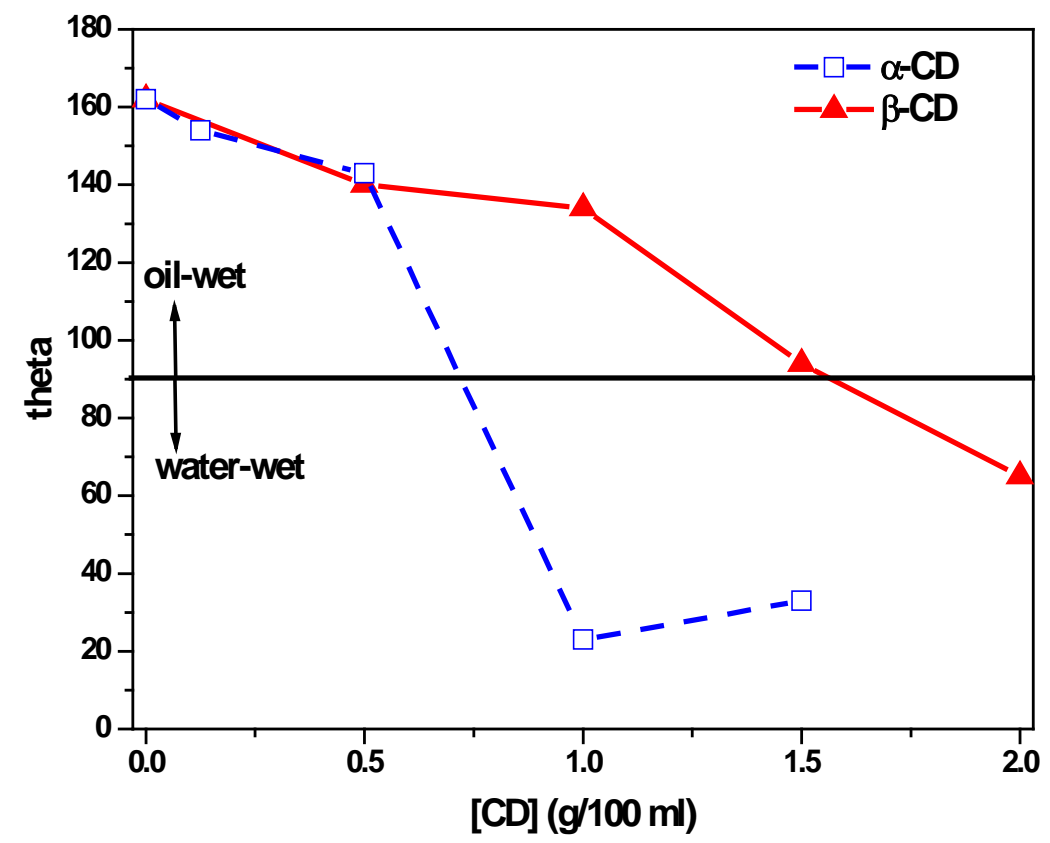

Figure 7. Effect of the CD concentration on the contact angles of an $n$-dodecane drop in contact with $\mathrm{C}_{18}$-quartz and immersed in the aqueous phase. The lines connecting the experimental points were added for easy reading.

However, the dynamic behavior of the $n$-dodecane drops at low $\mathrm{CD}$ concentrations was quite different from that observed with concentrated CD solutions. In diluted $\beta$-CD solutions $(<1 \% w / v)$, the drops behaved similarly to brine without CDs. The initially formed drops were stable for about $1 \mathrm{~min}$, and then relaxed within $10 \mathrm{~min}$ to a more spread final state, which remained unchanged for several hours (Figure 5 and Figure S2). As noted above, it takes ca. $30 \mathrm{~s}$ in our set up between injecting the drop and start recording the images. In Figure 5 and Figure S2, zero time is the moment the camera was triggered (ca. $30 \mathrm{~s}$ after drop deposition). In diluted $\alpha-\mathrm{CD}$ solutions, the relaxation process was much faster than with $\beta-C D$ and could not be recorded, since it was faster than the time needed to trigger the camera. 
In concentrated CD solutions (above the transition concentration in Figure 7), on the other hand, the shape of the $n$-dodecane drops changed very little with time, in contrast to the diluted solutions (Figure S2). Instead, membrane-like skins appeared at the oil drop surface within a few minutes as the drop was aged in concentrated CD solutions. Such semi-rigid skins seem to stabilize the drops, preventing them to spread on $\mathrm{C}_{18}$-quartz. This phenomenon can be explained by the precipitation of mycrocrystals of CD inclusion complexes [25], forming a film at the interface, as discussed below. The critical concentration observed in Figure 7 seems to be the onset of film formation.

\subsection{Aging of n-Dodecane Drops at High CD Concentrations}

When the $n$-dodecane drops were immersed in concentrated CD solutions (above the critical concentration seen in Figure 7), formation of films at the oil/water interface was clearly observed after ca. 5 min (Figure 8 and Figure S3). Similar phenomenon has been observed by other authors, and was attributed to the precipitation of microcrystals of $\mathrm{CD} /$ hydrocarbon inclusion complexes at the interface $[24,25]$. In the case of $\beta-C D$, the film had the appearance of a membrane-like wrinkled skin (Figure 8, top), and seemed to be fluid or semi-fluid at the interface. As seen in Figure S3, drops of $n$-dodecane in concentrated $\beta$-CD solutions started to spread in the first few minutes after contact (oil started advancing over a previously water-covered surface), but as the skin became more rigid the drop shape got frozen. This shows that the effects of CDs were both kinetic and thermodynamic. Changes in interfacial tensions will affect the wettability according to Equation (1), which is valid for systems in thermodynamic equilibrium. This was likely the case at low [CD]. At high [CD], however, skin formation prevented the system to reach the equilibrium, and the drop was frozen in a non-equilibrium shape.

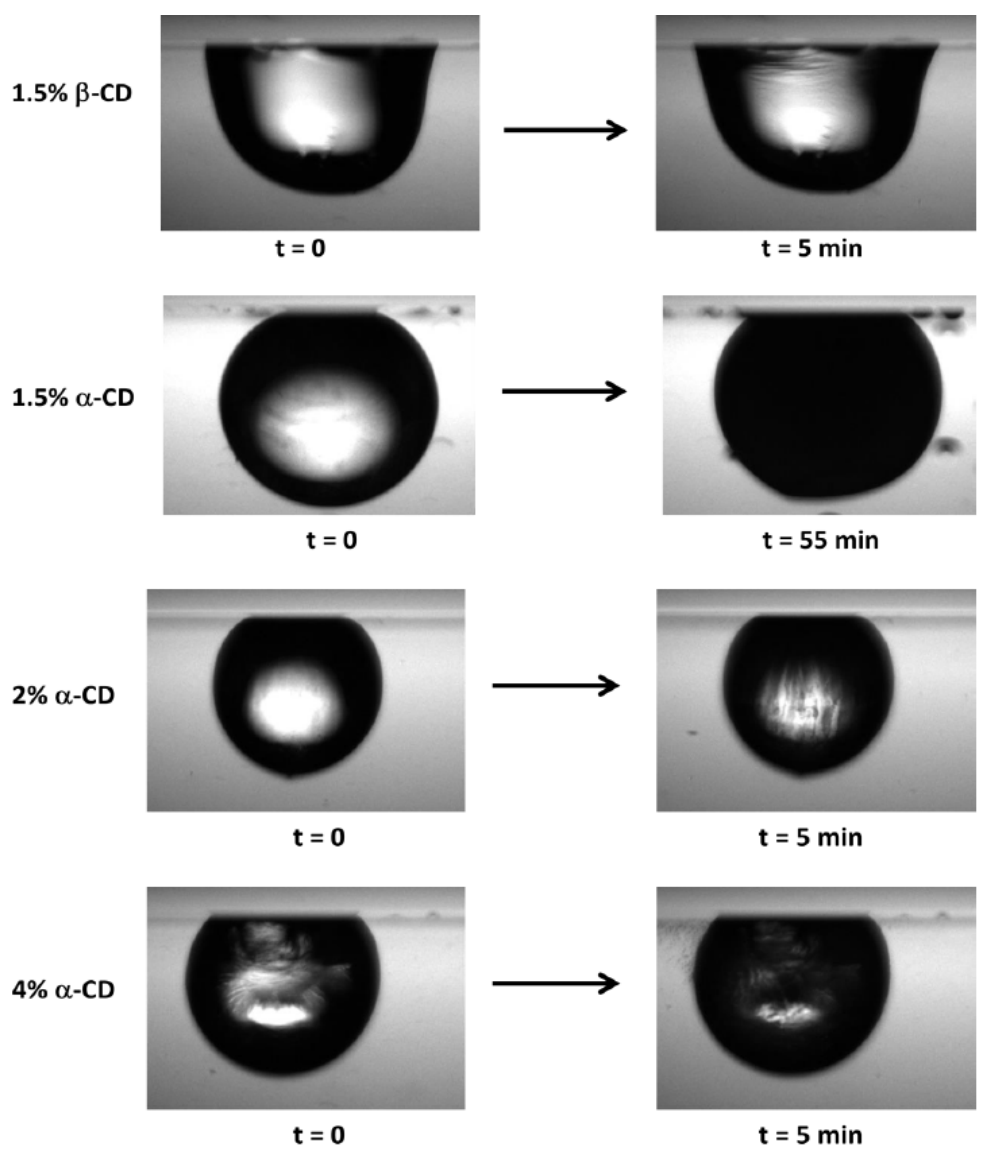

Figure 8. Images of $n$-dodecane drops in contact with a $C_{18}$-quartz surface and immersed in concentrated $\mathrm{CD}$ solutions (containing $0.6 \mathrm{M} \mathrm{NaCl}$ ). Notice the time-dependent formation of a solid layer of inclusion complexes at the oil/water interface. 
The behavior in the presence of concentrated $\alpha-C D$ was quite different. A solid crystalline layer precipitated at the drop surface (Figure 8), as seen by the darkening of the bright areas inside the drops. The images were acquired in light transmission mode, so that the bright areas at $t=0$ mean that the drops were initially translucent. The crystals formed after some time in the presence of $\alpha-C D$ blocked the light, resulting in the observed darkening. Since $\alpha$-CD is more soluble in water than $\beta-C D$, it was possible to extend the studies to higher concentrations (up to $5 \% w / v$ ). At very high $\alpha-C D$ concentrations, the interface became saturated with crystals and the excess of solid material was relayed into the aqueous phase as a flow of particles (Figure 8 and Figure S4). The crystals of $\alpha-\mathrm{CD} / n$-dodecane inclusion complexes were less dense that the aqueous phase and flowed up pushed by buoyancy forces (Figure S4).

Hernandez-Pascacio et al. [24] observed the formation of films of $\alpha-\mathrm{CD} /$ surfactant inclusion complexes at air/water interfaces. The films could be imaged at the interface using Brewster-angle microscopy and showed a similar aspect as the skins observed in Figure 8 and Figure S3. Mathapa and Paunov observed similar skins around $n$-tetradecane drops immersed in CD aqueous solutions, and showed that the phenomenon was due to the presence of microcrystals of $C D$ inclusion complexes [25]. They found out that the $\beta$-CD complexes with $n$-tetradecane formed flexible skins, stabilized by stable microcrystals, whereas larger crystals were formed with $\alpha-C D$, resulting in precipitation at the interface. Our results are in complete agreement with those findings.

The larger crystals verified with $\alpha$-CD arise because the $C D$ inclusion complexes have a trend to self-assemble in long nanotubes stabilized by hydrogen bonds. The threading of several CD units onto a polymeric chain results in the formation of the so-called pseudo-polyrotaxanes (also known as "molecular necklaces") $[24,25]$. In the present case several $n$-dodecane molecules within the CD cavities would play the role of the polymeric chain. Such tubular structures have been seen by microscopy at the interface of $n$-alkane drops with $\alpha$-CD solutions [25].

Other studies have shown the formation of CD-based oil-in-water Pickering emulsions (which are emulsions stabilized by solid particles), where the stabilizing particles at the interface were microcrystals of CD inclusion complexes with $n$-alkanes [26,33,34]. Several other oils were found to form CD-stabilized Pickering emulsions, such as squalane, soybean oil, liquid paraffin [35], medium chain triglycerides [36], olive oil, castor oil and coconut oil [37]. Such stable oil-in-water emulsions could be a mechanism for oil transport within the porous rock media, being an additional effect of CDs in EOR. Pickering emulsions have been often employed to facilitate oil flow in EOR studies [38,39].

The results above showed that $\alpha-C D$ was the most effective in altering the surface wettability among the CDs tested. This can be explained by the tight fit of the alkane chain within the narrower cavity of $\alpha-C D$, in contrast to a looser fit with $\beta-C D$ and $\gamma-C D[7,8]$. Inoue et al. [26] reported that $\alpha$-CD formed the most stable inclusion complex with $n$-dodecane among the native CDs. They also found, however, that complexes of $n$-dodecane with $\alpha$-CD were not as good emulsifying agents as those with $\beta$-CD and $\gamma$-CD. The $\alpha-C D / n$-dodecane complexes formed unstable emulsions and tended to precipitate as crystals. The $\beta-\mathrm{CD} / n$-dodecane and $\gamma-\mathrm{CD} / n$-dodecane complexes, on the other hand, formed stable layers of microcrystals at the oil drop surface, stabilizing the oil-in-water Pickering emulsions [26]. Those results are in agreement with the findings of the present work.

In view of the present results, it can be concluded that the use of $\alpha$-CD in EOR could be advantageous, since its effects were observed at lower concentrations (Figure 7). However, its use should be restricted to low concentrations, below or near the critical concentration, since the excess of crystals could clog the rock porous system. $\beta-C D$, on the other hand, shows a much lower trend to precipitate and therefore could be used for EOR applications above the critical concentration.

\subsection{Advancing and Receding Contact Angles}

Equilibrium contact angles do not always represent the real contact angles. It is often convenient to measure advancing and receding contact angles. It is generally accepted that advancing contact angles, which are the contact angles obtained when water is advancing over a solid surface previously 
covered by oil, represent better the reservoir wettability than the equilibrium or receding angles $[15,16]$. This is because in a water flooding operation, water advances over rock surfaces previously wet by oil. In the tensiometer used here, advancing and receding contact angles were measured by the tilting plate technique (Figure 9), where the stage bearing the drop was tilted using a tilting cradle accessory. The advancing and receding angles were registered in the same image (Figure 9) right after the drop started moving during tilting.

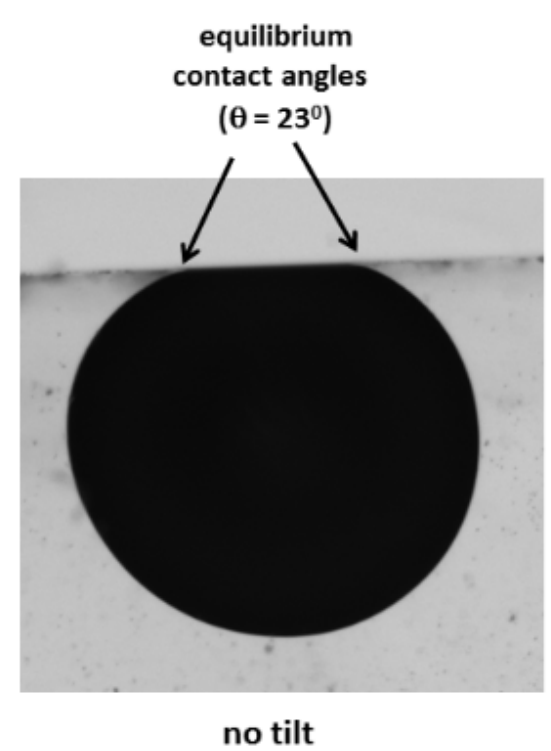

$\mathbf{A}$

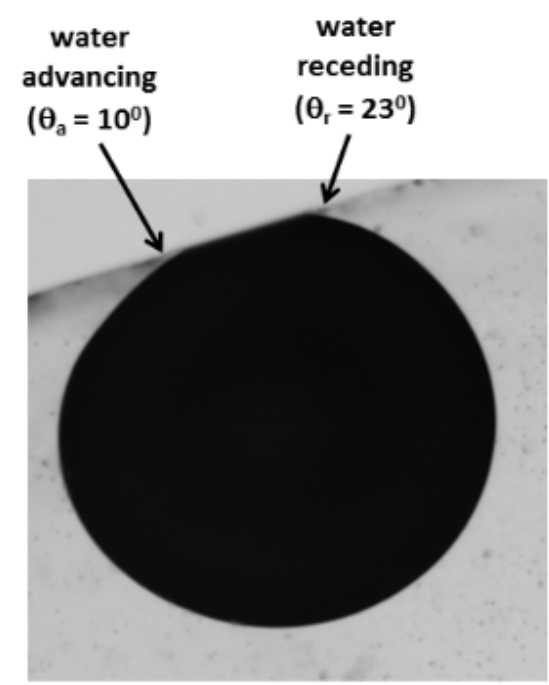

tilt angle $=15^{\circ}$

B

Figure 9. Tilting angle experiment with a drop of $n$-dodecane immersed in aqueous saline solutions $(0.6 \mathrm{M} \mathrm{NaCl})$ containing $1 \%(w / v) \alpha-\mathrm{CD}$ and in contact with $\mathrm{C}_{18}$-quartz. (A) Initial position (no tilt). (B) The same drop just after it started moving on the surface. It can be noticed the water advancing at the contact point on the left and receding at the contact point at the right side.

It was not easy to measure advancing and receding angles in the presence of CDs. With low CD concentrations, time-dependent drop relaxation, as described above, was concomitant with tilting. With high $C D$ concentrations, on the other hand, most drops were strongly adhered to the $C_{18}$-quartz substrate, and did not detach from the surface even when the quartz cuvette was turned upside down. The reason for the strong oil/ $\mathrm{C}_{18}$-quartz adhesion could be an interaction between $\mathrm{CD}$ inclusion complexes at the drop interface and surface octadecyl groups on quartz. The same CD molecule could host at the same time a surface octadecyl chain and a $n$-dodecane molecule from the drop surface, resulting in zipper-like attractive interactions. Adhesion of oil to rock surfaces even when those were strongly water-wet has been reported in the literature [15]. In a few favorable cases (near the critical concentration shown in Figure 7), it was possible to make the drop move on the solid surface, and hence advancing and receding contact angles could be obtained, as shown in Figure 9 for $1 \%(w / v)$ $\alpha$-CD. It can be seen that the water advancing contact angle was $10^{\circ}$, which is even more water-wet than the equilibrium angle of $23^{\circ}$, confirming the ability of Cyclodextrins in making the $\mathrm{C}_{18}$-quartz surface more water-wet.

\section{Conclusions}

The results presented here show that the CDs are prospective candidates for pseudo-surfactants with applications in EOR. CD-based pseudo-surfactants are formed upon inclusion of linear hydrocarbon chains within the CD cavities, resulting in inclusion complexes. The pseudo-surfactants were tested on octadecyl-covered surfaces representing oil-wet rock surfaces. Hydrocarbon drops were shown to spread well over these oil-wet surfaces, but the effects were reversed in the presence of the 
CDs. The most pronounced effects were found with $\alpha-C D$, in which case the oil-wet octadecyl-covered surface was changed to water-wet. The pronounced effects of $\alpha-C D$ can be explained by the tight fit of linear alkyl chains within the $\alpha$-CD cavity, forming stable inclusion complexes, whereas a looser fit is expected for the larger CDs. The effects of $\alpha$-CD were observed at relatively low concentrations, what is very important for the economic viability in EOR. At higher concentrations, the CD inclusion complexes form a microcrystalline layer around the hydrocarbon drop, resembling Pickering emulsions. The formation of CD-based Pickering emulsions could be explored for oil transport, although care must be taken to avoid pore-clogging by the microcrystals. Many more studies will be needed before the CDs can be introduced in real reservoirs, since it has not been used before for EOR operations. Nevertheless, the present results are encouraging for further investigations on the use of CDs in EOR. The next step in the research will be testing the CDs with asphaltene-covered surfaces.

Supplementary Materials: The following are available online www.mdpi.com/2504-5377/2/1/10/s1. Figure S1: Interfacial tension between a drop of dodecane and $\alpha-C D$ solutions of different concentrations in brine $(0.6 \mathrm{M}$ $\mathrm{NaCl}$ ) followed as a function of time. Figure S2: Dynamic behavior of the contact angles followed as a function of time for $n$-dodecane drops immersed in aqueous saline solution $(0.6 \mathrm{M} \mathrm{NaCl})$ containing $\beta$-CD and in contact with $\mathrm{C}_{18}$-quartz. Figure S3: drops of $n$-dodecane in contact with $\mathrm{C}_{18}$-quartz and immersed in aqueous saline solution $(0.6 \mathrm{M} \mathrm{NaCl})$ containing $1.5 \%(w / v) \beta$-CD. Figure S4: Drop of $n$-dodecane in contact with $\mathrm{C}_{18}$-quartz and immersed in aqueous saline solution $(0.6 \mathrm{M} \mathrm{NaCl})$ containing $5 \%(w / v) \alpha-C D$.

Acknowledgments: S.B. and C.R.M. acknowledge the support of Brazilian agencies FAPESP (grant No 2016/05496-2 and 2017/02317-2) and CNPq (grant No 480189/2011-0). The authors wish to thank FINEP/CTINFRA (call No 01/2010, ref. 1132/10) for the purchase of the Attension Theta Optical Tensiometer.

Author Contributions: S.B. and C.R.M. conceived and designed the experiments and wrote the paper. A.F.T.d.C. and R.D.S. performed the experiments.

Conflicts of Interest: The authors declare no conflict of interest. The funding sponsors had no role in the design of the study; in the collection, analyses, or interpretation of data; in the writing of the manuscript, and in the decision to publish the results.

\section{References}

1. Lake, L.W.; Johns, R.; Rossen, B.; Pope, G. Fundamentals of Enhanced Oil Recovery; Society of Petroleum Engineers: Richardson, TX, USA, 2014; ISBN 978-1-61399-328-6.

2. Howe, A.M.; Clarke, A.; Mitchell, J.; Staniland, J.; Hawkes, L.; Whalan, C. Visualising surfactant enhanced oil recovery. Colloids Surf. A Physicochem. Eng. Asp. 2015, 480, 449-461. [CrossRef]

3. Iglauer, S.; Wu, Y.; Shuler, P.J.; Tang, Y.; Goddard, W.A. New surfactant classes for enhanced oil recovery and their tertiary oil recovery potential. J. Pet. Sci. Eng. 2010, 71, 23-29. [CrossRef]

4. Anderson, W.G. Wettability literature survey. Part 2: Wettability measurement. J. Petr. Technol. 1986, 38, 1246-1262. [CrossRef]

5. Buckley, J.S. Effective Wettability of Minerals Exposed to Crude Oil. Curr. Opin. Colloid Interface Sci. 2001, 6, 191-196. [CrossRef]

6. Kumar, M.; Fogden, A. Patterned Wettability of Oil and Water in Porous Media. Langmuir 2010, 26, 4036-4047. [CrossRef] [PubMed]

7. Szejtli, J. Introduction and General Overview of Cyclodextrin Chemistry. Chem. Rev. 1998, 98, 1743-1754. [CrossRef] [PubMed]

8. Dodziuk, H. (Ed.) Cyclodextrins and Their Complexes: Chemistry, Analytical Methods, Applications; Wiley-VCH: Weinheim, Germany, 2006; ISBN 978-3-527-60844-7.

9. Horikoshi, K.; Shibanai, I.; Nakamura, N. Process for Production of Oil from Oil Sand. Patent CA 1117055 A1, 26 January 1982.

10. Horikoshi, K.; Kato, T.; Shibanai, I. Process for the Oil Extraction from Oil Sand by Using Cyclodextrin and Hydrocarbon Solvents. Patent CA 1208149 A1, 22 July 1986.

11. Leslie, T.; Xiao, H.; Dong, M. Tailor-modified starch/cyclodextrin-based polymers for use in tertiary oil recovery. J. Pet. Sci. Eng. 2005, 46, 225-232. [CrossRef]

12. Kjøniksen, A.L.; Beheshti, N.; Kotlar, H.K.; Zhu, K.; Nyström, B. Modified polysaccharides for use in enhanced oil recovery applications. Eur. Polym. J. 2008, 44, 959-967. [CrossRef] 
13. Wever, D.A.Z.; Picchioni, F.; Broekhuis, A.A. Polymers for enhanced oil recovery: A paradigm for structure-property relationship in aqueous solution. Prog. Polym. Sci. 2011, 36, 1558-1628. [CrossRef]

14. Adamson, A.W.; Gast, A.P. Physical Chemistry of Surfaces; Wiley-Interscience: New York, NY, USA, 1997.

15. Rao, D.N. Measurements of dynamic contact angles in solid-liquid-liquid systems at elevated pressures and temperatures. Colloids Surf. Physicochem. Eng. Asp. 2002, 206, 203-216. [CrossRef]

16. Drummond, C.; Israelachvili, J. Fundamental studies of crude oil-surface water interactions and its relationship to reservoir wettability. J. Pet. Sci. Eng. 2004, 45, 61-81. [CrossRef]

17. Yang, D.; Gu, Y.; Tontiwachwuthikul, P. Wettability determination of the reservoir brine-reservoir rock system with dissolution of $\mathrm{CO}_{2}$ at high pressures and elevated temperatures. Energy Fuels 2008, 22, 504-509. [CrossRef]

18. Bera, A.; Kissmathulla, S.; Ojha, K.; Kumar, T.; Mandal, A. Mechanistic study of wettability alteration of quartz surface induced by nonionic surfactants and interaction between crude oil and quartz in the presence of sodium chloride salt. Energy Fuels 2012, 26, 3634-3643. [CrossRef]

19. Serrano-Saldaña, E.; Domínguez-Ortiz, A.; Pérez-Aguilar, H.; Kornhauser-Strauss, I.; Rojas-González, F. Wettability of solid/brine/n-dodecane systems: Experimental study of the effects of ionic strength and surfactant concentration. Colloids Surf. Physicochem. Eng. Asp. 2004, 241, 343-349. [CrossRef]

20. Wu, Y.; Shuler, P.J.; Blanco, M.; Tang, Y.; Goddard, W.A., III. An experimental study of wetting behavior and surfactant EOR in carbonates with model compounds. SPE J. 2008, 13, 26-34. [CrossRef]

21. Hansen, G.; Hamouda, A.A.; Denoyel, R. The effect of pressure on contact angles and wettability in the mica/water/n-decane system and the calcite + stearic acid/water/n-decane system. Colloids Surf. Physicochem. Eng. Asp. 2000, 172, 7-16. [CrossRef]

22. Freer, E.M.; Svitova, T.; Radke, C.J. The role of interfacial rheology in reservoir mixed wettability. J. Pet. Sci. Eng. 2003, 39, 137-158. [CrossRef]

23. Lara, L.S.; Voltatoni, T.; Rodrigues, M.C.; Miranda, C.R.; Brochsztain, S. Potential applications of Cyclodextrins in enhanced oil recovery. Colloids Surf. Physicochem. Eng. Asp. 2015, 469, 42-50. [CrossRef]

24. Hernandez-Pascacio, J.; Garza, C.; Banquy, X.; Diaz-Vergara, N.; Amigo, A.; Ramos, S.; Castillo, R.; Costas, M.; Pinero, A. Cyclodextrin-Based Self-Assembled Nanotubes at the Water/Air Interface. J. Phys. Chem. B 2007, 111, 12625-12630. [CrossRef] [PubMed]

25. Mathapa, B.G.; Paunov, V.N. Self-assembly of cyclodextrin-oil inclusion complexes at the oil-water interface: A route to surfactant-free emulsions. J. Mater. Chem. A 2013, 1, 10836-10846. [CrossRef]

26. Inoue, M.; Hashizaki, K.; Taguchi, H.; Saito, Y. Preparation and characterization of n-alkane/water emulsion stabilized by cyclodextrin. J. Oleo Sci. 2009, 58, 85-90. [CrossRef] [PubMed]

27. Askvik, K.M.; Høiland, S.; Fotland, P.; Barth, T.; Grønn, T.; Fadnes, F.H. Calculation of wetting angles in crude oil/water/quartz systems. J. Colloid Interface Sci. 2005, 287, 657-663. [CrossRef] [PubMed]

28. Grate, J.W.; Dehoff, K.J.; Warner, M.G.; Pittman, J.W.; Wietsma, T.W.; Zhang, C.; Oostrom, M. Correlation of Oil-Water and Air-Water Contact Angles of Diverse Silanized Surfaces and Relationship to Fluid Interfacial Tensions. Langmuir 2012, 28, 7182-7188. [CrossRef] [PubMed]

29. Jia, H.; Leng, X.; Zhang, D.; Lian, P.; Liang, Y.; Wu, H.; Huang, P.; Liu, J.; Zhou, H. Facilely control the SDS ability to reduce the interfacial tension via the host-guest recognition. J. Mol. Liquids 2018, 255, 370-374. [CrossRef]

30. Bojinova, T.; Coppel, Y.; Viguerie, N.L.; Milius, A.; Rico-Lattes, I.; Lattes, A. Complexes between $\beta$-Cyclodextrin and Aliphatic Guests as New Noncovalent Amphiphiles: Formation and Physicochemical Studies. Langmuir 2003, 19, 5233-5239. [CrossRef]

31. Machut, C.; Mouri-Belabdelli, F.; Cavrot, J.-P.; Sayede, A.; Monflier, E. New supramolecular amphiphiles based on renewable resources. Green Chem. 2010, 12, 772-775. [CrossRef]

32. Dou, Z.-P.; Xing, H.; Xiao, J.-X. Hydrogenated and Fluorinated Host-Guest Surfactants: Complexes of Cyclodextrins with Alkanes and Fluoroalkyl-Grafted Alkanes. Chem. Eur. J. 2011, 17, 5373-5380. [CrossRef] [PubMed]

33. Mathapa, B.G.; Paunov, V.N. Cyclodextrin stabilised emulsions and cyclodextrinosomes. Phys. Chem. Chem. Phys. 2013, 15, 17903-17914. [CrossRef] [PubMed]

34. Inoue, M.; Hashizaki, K.; Taguchi, H.; Saito, Y. Emulsion Preparation Using $\beta$-Cyclodextrin and Its Derivatives Acting as an Emulsifier. Chem. Pharm. Bull. 2008, 56, 1335-1337. [CrossRef] [PubMed] 
35. Inoue, M.; Hashizaki, K.; Taguchi, H.; Saito, Y. Emulsifying Ability of $\beta$-Cyclodextrins for Common Oils. J. Dispers. Sci. Technol. 2010, 31, 1648-1651. [CrossRef]

36. Li, X.; Li, H.; Xiao, Q.; Wang, L.; Wang, M.; Lu, X.; York, P.; Shi, S.; Zhang, J. Two-way effects of surfactants on Pickering emulsions stabilized by the self-assembled microcrystals of $\alpha$-cyclodextrin and oil. Phys. Chem. Chem. Phys. 2014, 16, 14059-14069. [CrossRef] [PubMed]

37. Wu, L.; Liao, Z.; Liu, M.; Yin, X.; Li, X.; Wang, M.; Lu, X.; Lv, N.; Singh, V.; He, Z.; et al. Fabrication of non-spherical Pickering emulsion droplets by Cyclodextrins mediated molecular self-assembly. Colloids Surf. Physicochem. Eng. Asp. 2016, 490, 163-172. [CrossRef]

38. Sharma, T.; Velmurugan, N.; Patel, P.; Chon, B.H.; Sangwai, J.S. Use of Oil-in-water Pickering Emulsion Stabilized by Nanoparticles in Combination with Polymer Flood for Enhanced Oil Recovery. Pet. Sci. Technol. 2015, 33, 1595-1604. [CrossRef]

39. Langevin, D.; Poteau, S.; Henaut, I.; Argillier, J.F. Crude Oil Emulsion Properties and their Application to Heavy Oil Transportation. Oil Gas Sci. Technol. 2004, 59, 511-521. [CrossRef]

(C) 2018 by the authors. Licensee MDPI, Basel, Switzerland. This article is an open access article distributed under the terms and conditions of the Creative Commons Attribution (CC BY) license (http:// creativecommons.org/licenses/by/4.0/). 